\title{
Downward, upstream or downstream? Assessment of meio- and macrofaunal colonization patterns in a gravel-bed stream using artificial substrates
}

\author{
Maria Cristina Bruno ${ }^{1 *}$, Elisa Bottazzi ${ }^{2}$ and Giampaolo Rossetti ${ }^{2}$ \\ ${ }^{1}$ Fondazione Edmund Mach, Research and Innovation Centre, Via E. Mach 1, I-38010 S. Michele all'Adige (TN), Italy \\ 2 Department of Environmental Sciences, University of Parma, Parco Area delle Scienze 11/A, I-43124 Parma, Italy
}

Received 22 May 2012; Accepted 6 August 2012

\begin{abstract}
The aim of this research was to investigate three main movement patterns of meiofauna and macrofauna in the riverbed: (1) vertical (downwards) within the interstitial habitat; (2) downstream (negative rheotaxis); (3) upstream (positive rheotaxis). The study was conducted in two headwater streams in the Northern Apennines (Italy), during summer 2009. Sets of traps opening upwards, upstream and downstream to collect, respectively, organisms moving down into the sediment, and organisms with negative and positive rheotaxis, were placed in each sampling site. Benthic samples were collected as well, to compare the benthic community composition with the assemblages colonizing the traps. Meiofauna was the dominant component, representing $95 \%$ in benthos and $85 \%$ in traps. Vertical top-opened traps collected more taxonomic groups and more individuals of macro- and meiofauna than the horizontal traps, suggesting a dominance of movements deep within the substrate rather than horizontal patterns. Horizontal traps opening upstream (negative rheotaxis) were colonized by more individuals than the traps opening downstream (positive rheotaxis), demonstrating the great importance of movements directed downstream as a primary source of colonization of new areas. Temporary meiofauna (i.e., insect larvae), which was the dominant component of trap assemblages, displayed predominantly vertical movements, supporting the nursery and refuge function of the hyporheic habitat for taxa which spend only the early larval stages in the hyporheos. The results also stress the importance of including meiofauna in studies characterizing the lotic communities.
\end{abstract}

Key words: Meiofauna / colonization patterns / artificial substrates / mountain streams / hyporheic habitat

\section{Introduction}

Populations of freshwater invertebrates are known to continually redistribute themselves over the stream bed, especially after disturbance, and the recolonization process begins as soon as proper conditions are restored (Townsend, 1989; Hildrew and Giller, 1994; Robertson et al., 1995; Lancaster and Belyea, 1997; Robertson, 2000). In fact, fluvial systems are spatially heterogeneous (Pennak, 1988) and populations may survive in some habitat patches (e.g., Golladay and Hax, 1995; Palmer et al., 1995; Robertson et al., 1995). Faunal movements play an important role in regulating population densities, in facilitating reproduction and larval development, and in finding refugia from disturbances (Palmer et al., 1992; Robertson et al., 1995; Winterbottom et al., 1997). Dispersal capabilities of stream invertebrates are highly

\footnotetext{
*Corresponding author. cristina.bruno@fmach.it
}

species-specific (Lancaster et al., 1996; Bilton et al., 2001; Elliott, 2003).

The superficial layer of the hyporheic sediment or 'interstitial habitat' (Dole-Olivier and Marmonier, 1992) is well known to act as a refuge for benthic invertebrates (e.g., Brunke and Gonser, 1997), whose capability to colonize the interstitial habitat globally increases the resistance and resilience of stream communities (DoleOlivier et al., 1997; Ward et al., 1998). Many invertebrate taxa use the interstitial area as a nursery zone, for the deposition and incubation of eggs and the growth of young instars (Jacobi and Cary, 1996), or as refuge, against droughts (Boulton, 1989; Bo et al., 2006), high superficial temperatures (Boulton et al., 1998) or strong sheer stress during high-discharge events (Bruno et al., 2009) and catastrophic floods (e.g., Lancaster and Hildrew, 1993; Dole-Olivier et al., 1997). The interstitial habitat therefore plays a crucial role in the potential recolonization of benthic substrate, being a continuous 
source of colonists (Mackay, 1992; Elser, 2001; Fowler, 2002), although the temporal changes in hyporheic invertebrate communities are still poorly known (Marmonier et al., 2012).

Four main invertebrate movement patterns in the shallow hyporheic zone have been recognized: (1) vertical (upwards and downwards within the substratum), (2) downstream, (3) upstream and (4) lateral. (1) The interstitial habitat hosts a rich and diverse invertebrate community (Giller and Malmqvist, 1998), especially within the first $15 \mathrm{~cm}$ depth (Collier and Scarsbrook, 2000; Bo et al., 2006); superficial organisms tend in fact to move downwards, penetrating into the interstitial zone during increased disturbance intensity, and move upwards emerging from the sediment after suitable superficial conditions are re-established (Williams and Hynes, 1974). This shallow portion of sediment often acts as a nursery habitat for early life stages of several benthic invertebrates (Bretschko, 1992; Jacobi and Cary, 1996). Vertical movements can also be related to habitat changes occurring during the different phases of the life cycle, for instance Baetidae and several Plecoptera are known to actively exploit resources in the ground water system as well as seek protection from unfavourable situations in the surface environment for the early stages part of their life cycle (Williams, 1984; Marmonier et al., 1993; Gibert et al., 1994). (2) In lotic systems, downstream movement patterns (i.e., drift and negative rheotaxis) represent the main source of new colonists (Brittain and Eikeland, 1988; Allan, 1997; Sharpe and Downes, 2006). Drift is the most common passive dispersal mechanisms; downstream crawling movements are common in benthic organisms, although involving a smaller number of individuals (e.g., Richards and Minshall, 1988; Fenoglio et al., 2004). (3) Positive rheotaxis is a common movement pattern for several benthic taxa (Panek, 1991; Fenoglio et al., 2002; Elliott, 2003), and the hyporheic zone represents the main migratory corridor upstream for benthic organisms, because it is easier to move inside the hyporheic layer rather than against the flow on the surface (Dole-Oliver et al., 1997; Lencioni et al., 2007). Several authors interpreted such behaviour as a compensatory mechanism for downstream displacement caused by drift (e.g., Williams and Hynes, 1976; Williams and Williams, 1993). However, positive rheotaxis generally involve less taxa and abundances compared with drift (Elser, 2001; Fenoglio et al., 2002), thus it is still unclear whether upstream movements are aimed to compensate for drift or, more likely, represent a merely behavioural response to local biotic and abiotic conditions (Söderström, 1987; Elser, 2001). In addition, due to logistic difficulties in sampling, upstream movements have traditionally received less attention than drift (Bergey and Ward, 1989), and the relative importance of these processes has probably been underestimated (Downes and Keough, 1998). Nonetheless, positive rheotaxis is of particular interest because, unlike drift, it is always active and non-accidental (Allan, 1997). (4) Lateral movements (i.e., towards and from stream banks) are poorly studied and often occur through both drifting and walking when floodplains are inundated (Smock, 1994).

Our study focused on the two main components of benthic communities: meiofauna and macrofauna. Permanent meiofauna is represented by taxa whose dimensions fall within the $0-150 \mu \mathrm{m}$ size range throughout their life span, even as adults (McIntyre, 1969; Palmer and Strayer, 1996), whereas temporary meiofauna include larvae and juvenile stages of those taxa belonging to macrofauna in later stages, and whose size falls within meiofaunal dimensional range only during early larval stages (e.g., some Oligochaeta, Chironomidae and Ephemeroptera) (McIntyre, 1969; Schmid-Araya and Schmid, 1995; Palmer and Strayer, 1996). Since meiofauna is rarely collected using conventional macroinvertebrate protocols, most of the studies on invertebrate movements in the substrate have historically focused on macroinvertebrate assemblages, and macrofauna received more attention from ecological studies than meiofauna in lotic habitats (Robertson et al., 2000, Silver et al., 2002; Radwell and Brown, 2008). Moreover, meio- and macrofaunal communities have seldom been compared (Stead et al., 2003). The paucity of studies on lotic meiofauna leads to misinterpretation and underestimation of invertebrate communities, in terms of species richness (e.g., Hakenkamp and Morin, 2000; Robertson et al., 2000; Schmid et al., 2000), secondary production and biomass (e.g., Stead et al., 2005) and species interactions in food webs (e.g., Hildrew, 1992).

Artificial substrates are useful tools for the study of invertebrate colonization dynamics; although only in few studies they were predisposed to assess directional movement patterns (e.g., Elser, 2001; Fowler, 2002). Furthermore, there is a general paucity of studies using artificial substrates in Italian mountain streams (e.g., Fenoglio et al., 2002; Bo et al., 2006; Lencioni et al., 2006) and, to our knowledge, no studies have been carried out in the Emilia-Romagna Apenninic area.

Scope of our research was to assess: firstly, the quantitative and qualitative distribution of meiofauna and macrofauna in two headwater gravel streams; secondly, based on such distribution, the colonization patterns (positive and negative rheotaxis, and vertical movements inside riverbed) of meiofauna and macrofauna, by using artificial substrates deployed within the riverbed.

\section{Materials and methods}

The study was conducted in the headwaters of the Parma River, in the NE Apennines (Parma Province, northern Italy). Two first-order, $1.5 \mathrm{~km}$ long tributaries were selected: Acque Assai (AAS) and Roccaferrara (ROC) streams. Both streams are in natural conditions and located in an undisturbed deciduous forest, with torrential flow regime resulting in incision of the riverbanks, particularly at ROC. 
One reach approximately $10 \mathrm{~m}$ long was selected on each of the two streams: AAS at $890 \mathrm{~m}$ a.s.1., $44^{\circ} 26^{\prime} 54.68^{\prime \prime} \mathrm{N}, 10^{\circ} 01^{\prime} 30.20^{\prime \prime} \mathrm{E}$ and ROC at $638 \mathrm{~m}$ a.s.1., $44^{\circ} 28^{\prime} 24.90^{\prime \prime} \mathrm{N}, 10^{\circ} 02^{\prime} 48.70^{\prime \prime E}$. The two reaches were represented by a sequence of one riffle and one pool, with substrate mainly represented by gravel and cobble; macrophytes (vascular and non-vascular) were not recorded, but epilithic algae were present.

The fluvial functional index (FFI; APAT, 2007) was used to assess the physical and biological conditions of the reaches. Surface water temperature $\left({ }^{\circ} \mathrm{C}\right), \mathrm{pH}$ and conductivity $\left(\mu \mathrm{S} . \mathrm{cm}^{-1}\right)$ were measured on the field on the date the traps were deployed with a digital $\mathrm{pH}$ meter Eutech XS $\mathrm{pH} 6$, and a conductivity meter Eutech XS cond 6 .

Traps were built according to Lencioni et al. (2006) from 1-L PVC bottles, of $9 \mathrm{~cm}$ diameter. The openings were cut and inserted back inside out, creating a trap of $16 \mathrm{~cm}$ height; the traps were filled with gravel (diameter: 0.5$1.5 \mathrm{~cm}$ ) previously gathered along the same river stretch, and carefully washed to remove all invertebrates. The traps opening were closed with a plastic net (mesh size: $0.5 \mathrm{~cm}$ ), which allowed animals to freely enter the traps but, if necessary, leave them if their specific habitat requirements were not satisfied (Elser, 2001). The base of each bottle was cut-off and replaced with a $50 \mu \mathrm{m}$ net, permitting water to flow into the traps but preventing any loss of invertebrates.

Experimental activities were conducted in early summer; this sampling season was chosen because of the higher colonization rates recorded in this season by several studies (e.g., Shaw and Minshall, 1980; Winterbottom et al., 1997). On 16 June 2009, three sets of three traps were placed in each sampling site, two sets in the riffle and the third set in the pool. Each set was represented by one vertical trap opened upwards (V) and two horizontal traps opening one upstream $(\mathrm{N})$ and one downstream $(\mathrm{P})$ in order to collect, respectively, organisms moving downwards into the sediment, and organisms with negative and positive rheotaxis. Lateral movements were not investigated because, due to the incision of the riverbanks, they probably occur to a much smaller extent than those in the other directions we investigated. Traps were buried into the shallow stream sediment, at a depth which, in the case of the $\mathrm{V}$ traps, left the openings partially free from the sediment, in order to allow both surface and interstitial taxa to colonize them. Stones were placed around and on top of each trap to avoid any displacement. Traps were left in situ for 36 days, which is considered an exposure time sufficient to allow the complete substrate colonization (Rosenberg and Resh, 1982; Piscart et al., 2006). After this period, traps were collected and their content was carefully sieved and washed, separating invertebrates from cobbles and organic debris; the rinse-out water was filtered with two nets $(255$ and $50 \mu \mathrm{m})$ in order to separate meiofauna from macrofauna.

During the in situ permanence of the traps, the study area was struck by at least four heavy rainfall events, which caused major high flow pulses and as a consequence one of the upstream-opened $(\mathrm{N})$ traps placed in a riffle at
ROC was lost, and a total of 17 traps were successfully retrieved at the end of the deployment period.

Benthic samples were collected with a Surber bottom sampler when traps were deployed, in order to compare the benthic community composition with the assemblages colonizing the traps, as proposed by several studies (e.g., Winterbottom et al., 1997; Elser, 2001; Fenoglio et al., 2002; Fowler, 2002; Bo et al., 2006; Lencioni et al., 2006). Three replicates were taken in each sampling site, two in the riffle and one in the pool; the Surber sampler (area: $0.46 \mathrm{~m}^{2}$ ) was equipped with two nets, one inside the other (inner mesh: $255 \mu \mathrm{m}$; outer mesh: $50 \mu \mathrm{m}$ ) in order to collect both meiofauna and macroinvertebrates from the same sampling area, and allowing to separate them in the field. All the organisms collected were preserved in the field with $95^{\circ}$ ethanol and identified to the lowest possible taxonomic level in the laboratory, using a dissecting microscope.

Copepoda and Ostracoda were classified into the species level following Dussart (1967, 1969), Stoch (1998), Stoch and Bruno (2011) and Karaytug (1999) for Copepoda; and Meisch (2000) for Ostracoda. All other taxa were identified to the lowest possible level following Campaioli et al. (1994, 1999), Fochetti et al. (2009) and Lechthaler and Stockinger (2005). Some specimens were not classified at the highest rank adopted for the rest of their taxonomic groups, because of their early stage of development. All identified taxa were classified as permanent and temporary meiofauna, and as stygoxene, stygophile and stygobiont, based on the definition of Gibert et al. (1994), and on a review of published specialized literature and on recent data on the distribution of Italian fauna (Stoch, 2000-2006).

As the sampling units (i.e., traps and Surber samples) were not comparable, the matrix of all rough data (total number of each taxon per sample) of each meiofaunal and macrofaunal taxon was standardized (each taxon by total per sample), thus turning assemblage counts into relative percentages. A square-root transformation was performed to down-weight the contributions of quantitatively dominant species (Clarke and Gorley, 2006). A two-way PERMANOVA (Permutational multivariate ANOVA, Anderson, 2001) analysis was run on the Bray-Curtis similarity matrices of all invertebrates to test for significant effect on species assemblages between: sampling method, site and the interaction of the two. A two-way PERMANOVA was applied to the square-root transformed abundance data of traps to test for significant effects on species assemblages between: trap orientation, site, and the interaction of the two for all invertebrate assemblages, and for meiofauna and macrofauna separately. A one-way PERMANOVA was run on BrayCurtis similarity matrices of square-root transformed abundance data of traps to assess if the location of traps in riffles versus pools had a significant effect on meiofaunal, macrofaunal and all invertebrates assemblages. Non-metric multi-dimensional scaling (NMDS) ordinations were performed to visualize the similarities and differences in assemblages' composition. The nonparametric Mann-Whitney $U$-test, Friedman ANOVA 
and Wilcoxon signed-rank test were used to test for significant differences in total abundances. All analyses were performed using software PRIMER 6 ver. 6.1 .12 (Clarke and Gorley, 2006) with its add-on package PERMANOVA + ver. 1.0.2. (Anderson et al., 2008) and Statistica ver. 8.1 (StatSoft Inc., 2008).

\section{Results}

The evaluation of the environmental quality assessed with the FFI assigned both banks of AAC to the class "good", the right bank of ROC to "fair" and the left bank to "fair-good". This difference is due to the riverbank erosion characterizing ROC sampling site. Water temperature measured $18.9^{\circ} \mathrm{C}$ (AAS) and $16.4^{\circ} \mathrm{C}$ (ROC), $\mathrm{pH}$ 8.17 (AAS) and 7.86 (ROC), conductivity $505 \mu \mathrm{S} . \mathrm{cm}^{-1}$ (AAS) and $404 \mu \mathrm{S} . \mathrm{cm}^{-1}$ (ROC).

A total of 27284 organisms were collected in this study. For macroinvertebrates, because of difficulties in the identification of several organisms (i.e., early larval stages) 1959 out of 2110 individuals (1629 in traps, 330 in Surber samples) were effectively assigned to 38 taxa (genus or family for EPT, family for Diptera, family or higher rank for the few remaining taxa). For meiofauna, 24996 out of 25174 collected individuals (9734 in traps, 15262 in Surber samples) were disambiguously assigned to 32 taxa (species for Copepoda, species group or family for Ostracoda, order for Insecta, higher rank for remaining taxa). We collected an average of 668 invertebrates per trap or 668412 ind. $\mathrm{m}^{-3}$ (572588 ind. $\mathrm{m}^{-3}$ of meiofauna and 95824 ind. $\mathrm{m}^{-3}$ of macrofauna), and an average of 2599 invertebrates per Surber sample or 5649 ind. ${ }^{-2}$ (5530 ind. $\mathrm{m}^{-2}$ of meiofauna and 120 ind. $\mathrm{m}^{-2}$ of macrofauna). The standardized mean abundance of meiofauna and macrofauna differed significantly only in traps assemblages $(P$-value $=0.001$, Mann-Whitney $U$-test $)$, with a mean standardized abundance of meiofaunal individuals of 86 and 92, respectively for AAS and ROC, and a mean abundance of 14 and 8 macroinvertebrates.

\section{Preferential distribution of meio- and macrofauna}

The preferential distribution (i.e., relative abundance and composition) of meio- and macrofauna in the benthic and shallow hyporheic layer, in relation to their colonization potential, was assessed by characterizing the differences between benthic and trap assemblages.

The two-way crossed PERMANOVA (factor: METHOD $\times$ SITE) applied to all data (i.e., Surber + traps, meiofauna and macrofauna) indicated that: (i) Surber and traps selected different invertebrate assemblages (factor: METHOD; pseudo $F: 8.49, P<0.001$ ); (ii) the two sites had different assemblages (factor: SITE, pseudo $F$ : 2.91, $P=0.001$ ); (iii) the two methods selected different assemblages at each site (factor METHOD $\times$ SITE, pseudo $F: 4.14, P<0.001)$.

The assemblages collected with traps varied more (average Bray-Curtis similarity among traps: 57.5 ) than

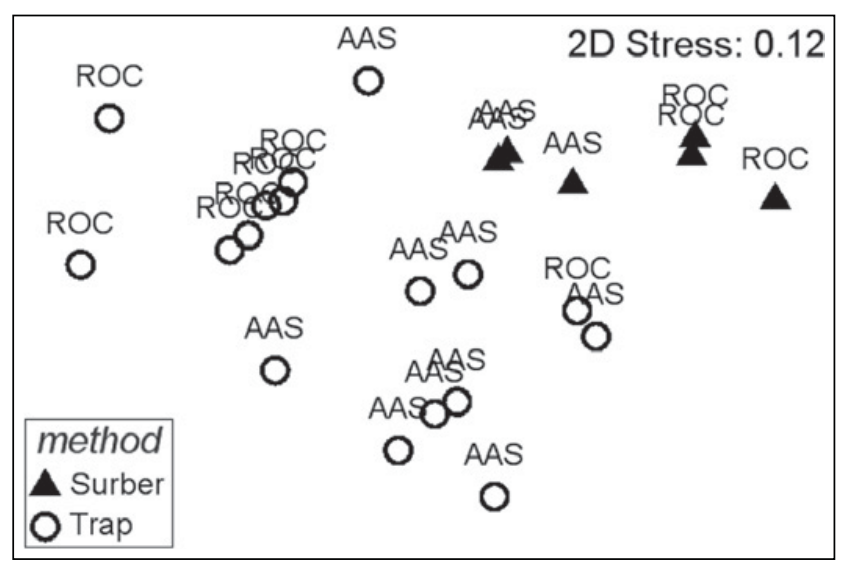

Fig. 1. Non-metric MDS plot of all faunal (meiofauna + macrofauna) data, square root transformed, based on BrayCurtis similarity index, in the two sampling sites [Acque Assai (AAS) and Roccaferrara (ROC)] for the two sampling methods.

Surber samples (average Bray-Curtis similarity among Surber samples: 72.0).

The nMDS plot (Fig. 1) showed a clear separation between assemblages collected with Surber versus those collected with traps, suggesting a strong effect of METHOD; the plot also shows a tendency for the samples from AAS to occur in the lower part of the plot, whereas the ROC samples occur in the upper part of the plot, indicating the effect of SITE. AAS Surber samples appeared to be more similar to trap samples than ROC Surber samples.

In general, meiofauna was the dominant component (Fig. 2), more in Surber samples $(95 \%$ of total invertebrates) than in traps $(85 \%)$, although traps were selective for several meiofaunal taxa: Harpacticoida, Cyclopoida, Ostracoda, Hydrachnidae, Nematoda, Tardigrada and Tricladida (Fig. 2). Temporary meiofauna was proportionally more abundant in Surber than in trap samples (91.6 and $69.9 \%$ of total invertebrates, respectively): for instance, early stages of Diptera (which were the most abundant meiofaunal taxon and represented mainly by Chironomidae, Fig. 2) represented 77.0 and $56.5 \%$, and early stages of Plecoptera 11.9 and $6.12 \%$, respectively, in Surber and traps. On the contrary, permanent meiofauna was proportionally more abundant in traps, where they represented $15.5 \%$ of the total, than in Surber $(3.2 \%)$ : for instance, Harpacticoida represented 5.2 and $0.9 \%$, Cyclopoida 2.2 and $0.1 \%$, Nematoda 5.3 and $0.7 \%$, respectively, in traps and Surber. Macrofauna was proportionally more abundant in traps $(14.7 \%)$ than in Surber samples $(5.2 \%)$, but the composition of macrofaunal assemblages were similar, with Diptera as dominant taxa, followed by EPT; Chironomidae were always dominant but they were proportionally more abundant in Surber samples. Bivalvia and Gastropoda were collected only with traps.

Organisms exclusive for traps were permanent meiofaunal taxa such as several Harpacticoida (Bryocamptus (Rheocamptus) typhlops, Bryocamptus (R.) zschokkei, Epactophanes richardi, Hypocamptus brehmi, H. cf. paradoxus and Moraria brevipes) and Cyclopoida 

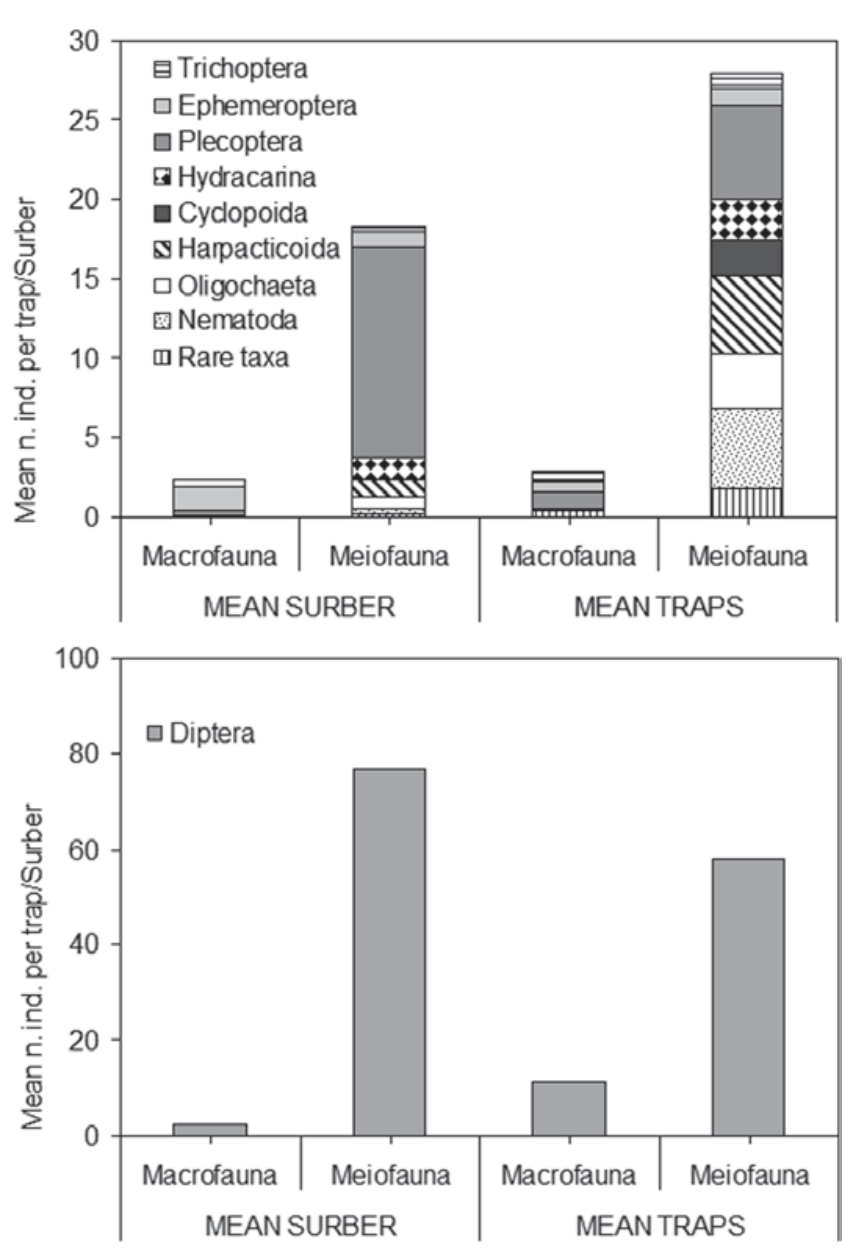

Fig. 2. Mean abundance of meiofauna and macrofauna grouped by higher taxonomic rank in each Surber or trap sample. Bottom: Diptera; Top: remaining taxa. Rare taxa: Tricladida, Coleoptera, Ostracoda, Tardigrada, Gastropoda and Bivalvia.

(Acanthocyclops einslei, Acanthocyclops magistridussarti, Diacyclops bisetosus, Graeteriella unisetigera, Microcyclops rubellus, Microcyclops varicans and Tropocyclops prasinus), and Dinocras and Leuctra (Plecoptera) Caenis and Habrophlebia (Ephemeroptera), Sericostomatidae (Trichoptera), Dytiscidae and Helodidae (Coleoptera), Gastropoda and Bivalvia for macrofauna. Taxa exclusive for Surber samples were several macrofaunal taxa: Perla (Plecoptera), Ecdyonurus, Electrogena and Torleya (Ephemeroptera), Glossosomatidae, Philopotamidae, Psychomidae and Rhyacophilidae (Trichoptera), Hydraenidae (Coleoptera), Anthomyiidae, Psychodidae, Simuliidae and Tabanidae (Diptera). Only one meiofaunal taxon, Candona cf. neglecta (Ostracoda), was exclusively collected in Surber samples, although it was very rare (two individuals in total).

\section{Colonization patterns of meiofauna and macrofauna}

The colonization patterns were assessed by comparing the preferential movements of meiofauna and macrofauna (positive and negative rheotaxis, and vertical movements).

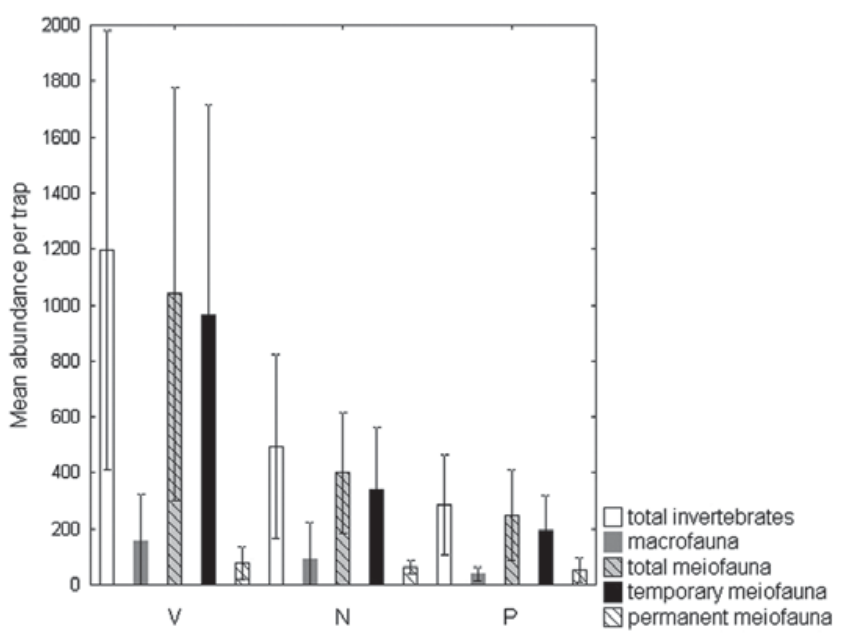

Fig. 3. Mean abundance for each trap orientation of total invertebrates, macrofauna, meiofauna, and the two subcategories (temporary and permanent) of meiofauna (V, vertical movement; $\mathrm{P}$, positive rheotaxis; $\mathrm{N}$, negative rheotaxis).

Overall, mean abundances of each taxon of all invertebrates and all macrofauna collected with different trap orientations did not differ (Friedman ANOVA, $P>0.05)$, whereas mean abundances of meiofaunal taxa differed among all orientations (Friedman ANOVA, $P=0.035)$. In particular, vertically top-opened traps (V) collected significantly more meiofauna than upstream $(\mathrm{N})$ and downstream $(\mathrm{P})$ opened traps (Wilcoxon test, V versus P: $P=0.015 ; \mathrm{V}$ versus N: $P=0.027$ ) (Fig. 3). Differences were significant for meiofauna for all pairs of orientations (Wilcoxon test, $\mathrm{V}$ versus $\mathrm{P}: P=0.002 ; \mathrm{P}$ versus $\mathrm{N}$ : $P=0.0287, \mathrm{~V}$ versus $\mathrm{N}: P=0.017$ ), with vertical traps which collected the highest number of meiofaunal individuals and respectively 4.2 and 2.6 times as many meiofaunal individuals as the downstream- and upstream-oriented horizontal traps (Fig. 3). The upstreamoriented traps collected 1.6 times as many meiofaunal individuals as the downstream oriented traps (Fig. 3). The comparison of assemblages composition of all invertebrates (i.e., meiofauna and macrofauna) over site and colonization direction, evaluated with the two-way crossed PERMANOVA (factor: ORIENTATION $\times$ SITE), indicated that: (i) traps with different orientation selected different invertebrate assemblages (factor: ORIENTATION; pseudo $F=2.32, P=0.014$ ); (ii) the two sites had different assemblages (factor: SITE, pseudo $F=4.15, P=0.001$ ); (iii) the three orientations did not select different assemblages in the two sites (factor ORIENTATION $\times$ SITE,$\quad P=0.302)$. The same PERMANOVA design applied to macrofauna and meiofauna separately, showed that: (i) for macrofauna, only sites had different assemblages (pseudo $F=2.52$, $P=0.016$ ); (ii) for meiofauna, traps orientation (pseudo $F=3.43, P=0.005$ ) and site (pseudo $F=5.098, P=0.002$ ) had a significant effect on assemblages. For those comparisons which differed significantly, the average Bray-Curtis similarity index provides and estimates the similarity between/within sites and between/within traps 
Table 1. Average Bray-Curtis similarity index between/within groups.

\begin{tabular}{|c|c|c|c|c|c|c|}
\hline & \multicolumn{2}{|c|}{ All invertebrates } & \multicolumn{2}{|c|}{ Meiofauna } & \multicolumn{2}{|c|}{ Macrofauna } \\
\hline & AAS & $\mathrm{ROC}$ & $\overline{\mathrm{AAS}}$ & $\overline{\mathrm{ROC}}$ & $\overline{\text { AAS }}$ & $\overline{\mathrm{ROC}}$ \\
\hline$\overline{\mathrm{AAS}}$ & 62.67 & & 64.31 & & 46.39 & \\
\hline \multirow[t]{3}{*}{ ROC } & 51.82 & 64.89 & 61.15 & 69.29 & 42.59 & 49.49 \\
\hline & \multicolumn{3}{|c|}{ All invertebrates } & \multicolumn{3}{|c|}{ Meiofauna } \\
\hline & $\mathrm{V}$ & $\bar{N}$ & $\mathrm{P}$ & $\overline{\mathrm{V}}$ & $\mathrm{N}$ & $\bar{P}$ \\
\hline$\overline{\mathrm{V}}$ & 65.73 & & & 70.21 & & \\
\hline $\mathrm{N}$ & 61.57 & 61.16 & & 65.83 & 67.47 & \\
\hline $\mathrm{P}$ & 54.76 & 60.23 & 56.60 & 57.96 & 64.75 & 61.78 \\
\hline
\end{tabular}

ASS, Acque Assai; ROC, roccaferrara; V, vertical movement; P, positive rheotaxis; N, negative rheotaxis.

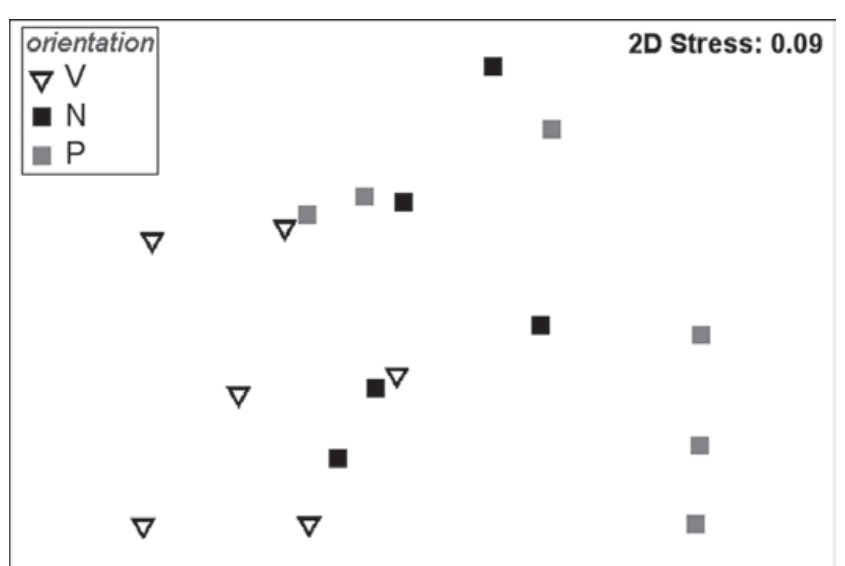

Fig. 4. Non-metric MDS plot of meiofauna data, square root transformed, based on Bray-Curtis similarity Index, for the three trap orientations $(\mathrm{V}$, vertical movement; $\mathrm{P}$, positive rheotaxis; $\mathrm{N}$, negative rheotaxis).

orientations. The assemblages of all invertebrates, macrofauna and meiofauna, collected with traps at AAS or ROC were more similar than when compared between the two sites (Table 1). The assemblages of all invertebrates and of meiofauna collected with $\mathrm{V}$ traps were the most similar, and those collected with the $\mathrm{P}$ traps the least similar (Table 1); when comparing pairs of traps, the $\mathrm{V}$ and $\mathrm{N}$ traps resulted the most similar, and $\mathrm{V}$ and $\mathrm{P}$ the least similar (Table 1). In the nMDS plot (Fig. 4), in fact, the V traps are quite separate from the $\mathrm{P}$ and $\mathrm{N}$ traps. The comparison of the riffle and pool data (one-way PERMANOVA, factor: RIFFLE/POOL) gave no significant results, indicating that the deployment of the traps in riffles or pools did not affect the assemblages' composition of all invertebrates, meiofauna and macrofauna.

For all orientations at all sampling sites, traps collected more temporary meiofauna than permanent meiofauna or macrofauna (Kruskal-Wallis for ecological category, over total number of individuals collected in all traps, $P=0.005$ ), although only seven taxa were ascribed to temporary meiofauna, and 24 and 26, respectively, to permanent meiofauna and macrofauna. The mean abundance of permanent meiofauna and macrofauna did not differ among orientation (Friedman ANOVA: $P>0.05$ ), whereas the abundance of temporary meiofauna differed significantly $(P<0.001)$, with vertical traps collecting more individuals overall, and more individuals of each taxon than the two horizontal ones. For horizontal traps, those opening upstream (negative rheotaxis) collected always more temporary individuals for each meiofaunal taxon than those opening downstream (positive rheotaxis).

Temporary meiofauna was represented mainly by early stages of Diptera $(87 \%$ of temporary meiofauna and $56.5 \%$ of all fauna collected in traps) and Plecoptera $(6 \%$ of temporary meiofauna and $1.1 \%$ of all fauna collected in traps), which were both more abundant in V traps. These same taxa were proportionally more abundant in the benthic layer (i.e., Surber samples) than in traps, whereas their later stages (macrofaunal size) were also the most abundant taxa, but were proportionally more abundant in traps. With these exceptions, higher percentage abundances were recorded in traps compared with Surber samples for all the remaining temporary meiofaunal taxa (i.e., Oligochaeta, Ephemeroptera, Trichoptera and Coleoptera).

Although differences among orientations were not significant, for both macrofauna and permanent meiofauna, $\mathrm{V}$ traps collected more individuals followed by $\mathrm{N}$ and $\mathrm{P}$ traps (Fig. 3). For permanent meiofauna, some taxa were exclusively found in one trap orientation (supplementary online Table). Taxa with downwards movements were the harpacticoids Hypocamptus brehmi and M. brevipes, the cyclopoid $A$. einslei and Tardigrada; taxa with exclusively negative rheotaxis: the cyclopoids $D$. bisetosus and $G$. unisetigera; taxa with exclusively positive rheotaxis: the harpacticoid $E$. richardi, the cyclopoids $A$. magistridussarti and $M$. rubellus and the ostracods Cyprididae (supplementary online Table). Differences in macroinvertebrates abundances did not emerge, possibly due to the reduced number of organisms collected (Fig. 3).

\section{Discussion}

Our study confirmed the constant, strong movements and colonization potential of meiofauna and macrofauna in mountain streams (Williams and Williams, 1993), and the high abundance and diversity of meiofauna in headwater streams with temporary meiofauna represented 
by insect larvae being dominant (Radwell and Brown, 2008).

\section{Preferential distribution of meio- and macrofauna}

Comparison between benthic (i.e., Surber samples) and shallow hyporheic (i.e., traps) assemblages highlighted how dispersal capabilities of invertebrates are taxon dependent (Lancaster et al., 1996; Bilton et al., 2001; Elliott, 2003): some taxa were exclusive of benthic samples, while others were found only in the shallow hyporheic, and overall the two assemblages differed. Several macrofaunal taxa did not colonize the traps, showing reduced dispersal ability, or the shallow hyporheic was not a suitable habitat for these taxa. Several other taxa were collected only in traps and seemed to be exclusive of the shallow hyporheic, and this was especially true for meiofaunal organisms which, in lotic environments, are more abundant within the first $15 \mathrm{~cm}$ of depth (Ward and Palmer, 1994; Collier and Scarsbrook, 2000; Bo et al., 2006). Most of these shallow-hyporheic taxa belonged to Copepoda Harpacticoida (13 species), not surprising since they are one of the major components of hyporheic fauna (Rouch, 1991). Other exclusive taxa were Tricladida (meiofauna), some insect larvae and molluscs (macrofauna).

The higher variability observed in traps highlights the patchy nature of meiofauna (Ward and Palmer, 1994), particularly of permanent meiofauna, which was more abundant in the shallow hyporheic than in benthos. The permanent meiofauna is in fact very diverse, comprising immature and adult nematodes, mites, oligochaetes, microcrustaceans, rotifers and other taxa that must spend all their life stages in the hyporheic zone (Hakenkamp and Palmer, 2000; Ward et al., 2000; Boulton, 2007). A particular category of permanent meiofauna is represented by stygobiotic taxa, which are exclusive to the hyporheic zone and other groundwater habitats during their entire life cycle, exhibiting ecomorphological adaptations to the biotic and abiotic conditions of groundwater (Gibert et al., 1994; Hancock et al., 2005). In the hyporheic zone, stygobites are typically found either in the 'phreatic zone' sensu Boulton et al. (1992) or in upwelling zones (Claret et al., 1999). In the present study, only two stygobiotic taxa were collected, and most likely were exclusively of the interstitial (i.e., collected only in horizontal traps): the Copepoda Cyclopoida $A$. magistridussarti, recorded so far only from caves, hyporheic habitats, and springs in the Apennines (Stoch and Bruno, 2011), and G. unisetigera which, in Europe, is quite well distributed and has been collected mainly in groundwater habitats (Fiers and Ghenne, 2000).

The higher proportional abundance of temporary meiofauna recorded in the benthic layer compared with the shallow hyporheic, might reflect the composition of temporary meiofauna, which mainly consists of early instars, especially of insects, that reside in the hyporheic zone, whereas later life stages of these species predominate in the benthos (Williams, 1984). The benthic layer thus represents the source of temporary meiofauna, which actively moves from there, deeper into the hyporheic sediment. In fact, due to seasonality in life cycles, most of the EPT taxa were just emerged from the eggs, and had not moved into the hyporheic layer.

Macrofauna was as well proportionally more abundant in the benthic layer, as expected since this is the preferential habitat for organisms with larger body size and later developmental stage than the meiofaunal ones. The density of macrofauna collected in the traps was similar to what was reported by Fenoglio et al. (2002) and Bo et al. (2006) for a similar colonization time in traps set in a section of the Apennines adjacent to the one investigated here, although in different watersheds, and represented mainly by small- or medium-sized, short-lived crawlers with aquatic respiration. It is worthy to note that we collected specimens of benthic Dytiscidae exclusively in traps; Fenoglio et al. (2006) recorded both larval and adult stages of the Dytiscidae Agabus (Gaurodytes) paludosus within the interstitial zone of the streambed of the Po River (North-Western Italy) during droughts. Our data support the hypothesis that surface taxa such as Coleoptera can utilize the hyporheic as refuge, or possibly feeding area.

Benthic taxa have been reported as being more abundant in the hyporheic zone in downwelling areas (upstream end of riffles, gravel bars, channel steps and at the concave part of meander beds) being transported passively by the flow (Boulton, 2000). In our study, we could not detect the effect of up or downwelling on invertebrate colonization, since no differences were detected between traps set in riffle versus pools, contrary to what reported in the literature (e.g., Franken et al., 2001; Sliva and Williams, 2005). This lack of significant differences was probably due to the scarcely clogged sediment and due to the resulting relatively homogenous hydrological and geomorphological conditions of the experimental reaches, within a fairly constant sediment space and dissolved oxygen content. These two factors are known to be main determinants of faunal distribution in the interstitial habitats of alluvial rivers (Brunke and Gonser, 1997).

Rheophilic (Simuliidae, Heptageniidae and Rhyachophilidae) taxa were not collected in the interstitial zone, even though some traps were located in a riffle, i.e., an area that is potentially suitable for this category of invertebrates. However, probably the inherent need of reophilic taxa for current, related to their feeding and respiratory requirements, cannot be adequately satisfied within the interstitial habitat where flow is always considerably lower than in the stream (Packman and Bencala, 2000).

\section{Colonization patterns of meiofauna and macrofauna}

Lotic meiofaunal communities demonstrate extremely variable dynamics, especially at small spatial scales of less than $1 \mathrm{~m}$ (Swan and Palmer, 2000); many meiofaunal taxa 
are quite mobile and colonization of new habitats is rapid at the patch scale, namely hours or days (Robertson, 2000). Schmid-Araya (2000) assessed invertebrate recolonization of a second-order gravel stream in Lower Austria, and reported very fast processes in the shallow hyporheic layer $(0-20 \mathrm{~cm})$, with meiofaunal and macrofaunal reached maximum densities after only $66 \mathrm{~h}$.

We detected preferential directions of movements (positive and negative rheotaxis, and vertical movements) for different categories of invertebrates. Vertical topopened traps collected more taxonomic groups and more individuals of both macro- and meiofauna than the horizontal traps, suggesting a dominance of movements deep within the substrate rather than horizontal patterns (positive and negative rheotaxis). In particular, traps were colonized more by invertebrates with negative rheotaxis than with positive rheotaxis, demonstrating the great importance of movements directed downstream as a primary source of colonization of new areas (Townsend and Hildrew, 1976; Bird and Hynes, 1981; Allan, 1997). Similar results were reported by Fenoglio et al. (2002) when comparing traps capturing invertebrates with positive or negative rheotaxis. The higher abundances in topopened traps may be interpreted as an attempt by invertebrates to escape from strong disturbance phenomena such as floods (Lancaster and Hildrew, 1993; DoleOlivier et al., 1997).

In the present study, temporary meiofauna showed preferential movement into the sediment, supporting the nursery and refuge function of the hyporheic habitat. Permanent meiofauna and macrofauna were similarly represented in all three traps and thus appeared not to have any preferential movement. For permanent meiofauna, in fact, the hyporheic is the exclusive habitat, and preferential downstream movements were not expected. For macrofauna, the lack of preferential movements suggests no privileged recolonization path (lack of faunal depletion in the area?), or movements associated, for instance, to trophic needs (trophic resources evenly distributed over a short-scale?).

This study presents only some preliminary results, and more investigation is necessary to better evaluate the effects of seasonality on meio- and macrofauna distribution and colonization patterns, especially for temporary meiofauna whose presence in the hyporheic is strongly related to the seasonality of their life cycles. Nonetheless, we can confirm what already was shown by Bo et al. (2006) and Fenoglio et al. (2002) for NW Apennine lotic systems, i.e., that headwaters of gravel riverbeds sustain rich and diversified invertebrate assemblages that actively move within the substratum and which have a composition and structure quite different from those of the surface streambed communities. In conclusion, our findings indicate that the hyporheos is an important component of the biological and ecological system of small creeks, and it represents a key habitat for stream macrobenthos (Del Rosario and Resh, 2000; Fenoglio et al., 2006), for both late larval stages (i.e., macrofauna) and early larval stages (i.e., temporary meiofauna such as early larval stages of insects), although such habitat may not be used by all taxa, as already reported by several studies (e.g., Bo et al., 2006).

Acknowledgements. We thank Simone Guareschi, Alex Laini (Parma University) for helping in the field activities. This study was financially supported by the Province of Parma (Project “Ambienti Acquatici dell'Appennino").

\section{References}

Allan J.D., 1997. Stream Ecology. Structure and Function of Running Waters, Chapman and Hall, London, 388 p.

Anderson M.J., 2001. A new method for non-parametric multivariate analysis of variance. Aust. Ecol., 26, 32-46.

Anderson M.J., Gorley R.N. and Clarke K.R., 2008. PERMANOVA + for PRIMER: Guide to Software and Statistical Methods, Primer-E, Plymouth, 214 p.

APAT, 2007. IFF 2007 - Indice di Funzionalità Fluviale. Nuova versione del metodo revisionata e aggiornata, Manuale APAT, Trento, $325 \mathrm{p}$.

Bergey E.A. and Ward J.V., 1989. Upstream-downstream movements of aquatic invertebrates in a Rocky mountain stream. Hydrobiologia, 185, 71-82.

Bilton D.T., Freeland J.R. and Okamura B., 2001. Dispersal in freshwater invertebrates. Annu. Rev. Ecol. Syst., 32, 159-181.

Bird G.A. and Hynes H.B.N., 1981. Movement of immature aquatic insects in a lotic habitat. Hydrobiologia, 77, 103-112.

Bo T., Cucco M., Fenoglio S. and Malacarne G., 2006. Colonisation patterns and vertical movements of stream invertebrates in the interstitial zone: a case study in the Apennines, NW Italy. Hydrobiologia, 568, 67-78.

Boulton A.J., 1989. Over-summering refuges of aquatic macroinvertebrates in two intermittent streams in central Victoria. Trans. R. Soc. South Aust., 113, 23-34.

Boulton A.J., 2000. The subsurface macrofauna. In: Jones J.B. and Mulholland P.J. (eds), Streams and Ground Waters, Academic Press, San Diego, 337-361.

Boulton A.J., 2007. Hyporheic rehabilitation in rivers: restoring vertical connectivity. Freshwater Biol., 52, 632-650.

Boulton A.J., Findlay S., Marmonier P., Stanley E.H. and Vallet H.M., 1998. The functional significance of the hyporheic zone in streams and rivers. Annu. Rev. Ecol. Syst., 29, 59-81.

Boulton A.J., Valett H.M. and Fisher S.G., 1992. Spatial distribution and taxonomic composition of the hyporheos of several Sonoran Desert streams. Arch. Hydrobiol., 125, $37-61$.

Bretschko G., 1992. Differentiation between epigeic and hypogeic fauna in gravel streams. Regul. River, 7, 17-22.

Brittain J.E. and Eikeland T.J., 1988. Invertebrate drift - a review. Hydrobiologia, 166, 77-93.

Brunke M. and Gonser T., 1997. The ecological significance of exchange processes between rivers and groundwater. Freshwater Biol., 37, 1-33.

Bruno M.C., Maiolini B., Carolli M. and Silveri L., 2009. Impact of hydropeaking on hyporheic invertebrates in an Alpine stream (Trentino, Italy). Ann. Limnol. - Int. J. Lim., 45, 157170.

Campaioli S., Ghetti P.F., Minelli A. and Ruffo S., 1994. Manuale per il riconoscimento dei macroinvertebrati delle 
acque dolci italiane, Vol. I. Provincia Autonoma di Trento, Trento, $357 \mathrm{p}$.

Campaioli S., Ghetti P.F., Minelli A. and Ruffo S., 1999. Manuale per il riconoscimento dei macroinvertebrati delle acque dolci italiane, Vol. II. Provincia Autonoma di Trento, Trento, $484 \mathrm{p}$.

Claret C., Marmonier P., Dole-Olivier M.-J., Creuzé des Châtelliers M., Boulton A.J. and Castella E., 1999. A functional classification of interstitial invertebrates: supplementing measures of biodiversity using species traits and habitat affinities. Arch. Hydrobiol., 145, 385-403.

Clarke K.R. and Gorley R.N., 2006. PRIMER-E ${ }^{\circledR}$ (v6). User Manual/Tutorial, PRIMER-E Ltd, Plymouth, 190 p.

Collier K.J. and Scarsbrook M.R., 2000. Use of riparian and hyporheic habitats. In: Collier K.J. and Winterbourn M.J. (eds.), New Zealand Stream Invertebrates: Ecology and Implications for Management, New Zealand Limnological Society, Christchurch, 179-206.

Del Rosario R.B. and Resh V.H., 2000. Invertebrates in intermittent and perennial streams: is the hyporheic zone a refuge from drying? J. N. Am. Benthol. Soc., 19, 680-696.

Dole-Olivier M.-J. and Marmonier P., 1992. Patch distribution of interstitial communities: prevailing factors. Freshwater Biol., 27, 177-191.

Dole-Olivier M.-J., Marmonier P. and Beffy J.L., 1997. Response of invertebrates to lotic disturbance: is the hyporheic zone a patchy refugium? Freshwater Biol., 37, 257-276.

Downes B.J. and Keough M.J., 1998. Scaling of colonization processes in streams: parallels and lessons from marine hard substrata. Aust. J. Ecol., 23, 8-26.

Dussart B.H., 1967. Les Copépodes des eaux continentales d'Europe occidentale. Tome I: Calanoïdes et Harpacticoïdes, N. Boubée et Cie, Paris, 500 p.

Dussart B.H. 1969. Les Copépodes des Eaux Continentales d'Europe Occidentale. Tome II: Cyclopoïdes et Biologie, N. Boubée et Cie, Paris, 292 p.

Elliott J.M., 2003. A comparative study of the dispersal of 10 species of stream invertebrates. Freshwater Biol., 48, 16521668.

Elser P., 2001. Assessing small-scale directional movements of benthic invertebrates in streams by using a multidirectional cage trap. Limnologica, 31, 119-128.

Fenoglio S., Agosta P., Bo T. and Cucco M., 2002. Field experiments on colonization and movements of stream invertebrates in an Apennine river (Visone, NW Italy). Hydrobiologia, 474, 125-130.

Fenoglio S., Bo T., Gallina G. and Cucco M., 2004. Vertical distribution in the water column of drifting stream macroinvertebrates. J. Freshwater Ecol., 19, 485-492.

Fenoglio S., Bo T. and Bosi G., 2006. Deep interstitial habitat as refuge for Agabus paludosus (Fabricius, 1801) (Coleoptera: Dytiscidae) during summer droughts. Coleopts Bull., 60, 37-41.

Fiers F. and Ghenne V., 2000. Cryptozoic copepods from Belgium: diversity and biogeographic implications. Belg. $J$. Zool., 130, 11-19.

Fochetti R. and Tierno De Figueroa J.M., 2009. Plecoptera, Vol. 43, Fauna d'Italia, Calderini, Bologna, 339 p.

Fowler R.T., 2002. Relative importance of surface and subsurface movement on benthic community recovery in the Makaretu River, North Island, New Zealand. N. Z. J. Mar. Fresh., 36, 459-469.
Franken R.J.M., Storey R.G. and Williams D.D., 2001. Biological, chemical and physical characteristics of downwelling and upwelling zones in the hyporheic zone of a north-temperate stream. Hydrobiologia, 444, 183-195.

Gibert J., Stanford J., Dole-Olivier M.-J. and Ward J.V., 1994. Basic attributes of ground water ecosystems and prospects for research. In: Gibert J., Danielopol D.L. and Stanford J. (eds), Ground Water Ecology, Academic Press, San Diego, $7-40$.

Giller P.S. and Malmqvist B., 1998. The Biology of Streams and Rivers, Oxford University Press, Oxford, 296 p.

Golladay S.W. and Hax C.L., 1995. Effects of an engineered flow disturbance on meiofauna in a northTexas prairie stream. J. N. Am. Benthol. Soc., 14, 404-413.

Hakenkamp C.C. and Morin A., 2000. The importance of meiofauna to lotic ecosystem functionality. Freshwater Biol., 44, 165-175.

Hakenkamp C.C. and Palmer M.A., 2000. The ecology of hyporheic meiofauna. In: Jones J.B. and Mulholland P.J. (eds.), Streams and Ground Waters, Academic Press, San Diego, 307-336.

Hancock P.J., Boulton A.J. and Humphreys W.F., 2005. Aquifers and hyporheic zones: towards an ecological understanding of groundwater. Hydrogeol. J., 13, 98-111.

Hildrew A.G., 1992. Food web and species interactions. In: Calow P. and Petts G.E. (eds.), The Rivers Handbook, Blackwell Scientific, Oxford, 309-330.

Hildrew A.G. and Giller P.S., 1994. Patchiness, species interactions and disturbance in the stream benthos. In: Giller P.S., Hildrew A.G. and Rafaelli D.G. (eds.), Aquatic Ecology: Scale, Pattern and Process, Blackwell Scientific Publications, Oxford, 21-62.

Jacobi G.Z. and Cary S.J., 1996. Winter stoneflies (Plecoptera) in seasonal habitats in New Mexico, USA. J. N. Am. Benthol. Soc., 15, 690-699.

Karaytug S., 1999. Copepoda: Cyclopoida. Genera Paracyclops, Ochridacyclops and key to the Eucyclopinae. Guides to the Identification of the Microinvertebrates of the Continental Waters of the World No. 14, Backhuys Publishers, Leiden, $224 \mathrm{p}$.

Lancaster J. and Belyea L.R., 1997. Nested hierarchies and scaledependence of flow refugium use. J. N. Am. Benthol. Soc., 16, 221-238.

Lancaster J. and Hildrew A.G., 1993. Flow refugia and microdistribution of lotic macroinvertebrates. J. N. Am. Benthol. Soc., 12, 385-393.

Lancaster J., Hildrew A.G. and Gjerlov C., 1996. Invertebrate drift and the longitudinal transport processes in streams. Can. J. Fish. Aquat. Sci., 53, 572-582.

Lechthaler W. and Stockinger W., 2005. Trichoptera - Key to Larvae from Central Europe, CD-Rom-Edition, Vienna.

Lencioni V., Maiolini B. and Oss M., 2007. Continuità verticale e biodiversità dello zoobenthos in torrenti alpini. St. Trent. Sci. Nat., Acta Biol., 83, 15-20.

Lencioni V., Maiolini B., Fochetti R., Grasso M., Boscaini A. and Dumnicka E., 2006. Artificial substrate colonization by invertebrates in two high altitude alpine streams. Verh. Internat. Verein. Limnol., 29, 1866-1870.

Mackay R.J., 1992. Colonization by lotic macroinvertebrates: a review of processes and patterns. Can. J. Fish. Aquat. Sci., 49, $617-628$. 
Marmonier P., Vervier P., Gibert J. and Dole-Olivier M.-J., 1993. Biodiversity in ground waters. TREE, 8, 392-395.

Marmonier P., Archambaud G., Belaidi N., Bougon N., Breil P., Chauvet E., Claret C., Cornut J., Datry T., Dole-Olivier M.J., Dumont B., Flipo N., Foulquier A., Gérino M., Guilpart A., Julien F., Maazouzi C., Martin D., Mermillod-Blondin F., Montuelle B., Namour P., Navel S., Ombredane D., Pelte T., Piscart C., Pusch M., Stroffek S., Robertson A., SanchezPérez J.-M., Sauvage S., Taleb A., Wantzen M. and Vervier P., 2012. The role of organisms in hyporheic processes: gaps in current knowledge, needs for future research and applications. Ann. Limnol. - Int. J. Lim., 48, 253-266.

McIntyre A.D., 1969. Ecology of marine meiobenthos. Biol. Rev. Biol. P. Camb., 44, 245-290.

Meisch C., 2000. Freshwater Ostracoda of Western and Central Europe. Spektrum Academischer Verlag GmbH, Heidelberg, Berlin, $522 \mathrm{p}$.

Packman A.I. and Bencala K.E., 2000. Modeling methods in the study of surface-subsurface hydrologic interactions. In: Jones J.B. and Mulholland P.J. (eds.), Streams and Ground Waters, Academic Press, San Diego, California, 45-80.

Palmer M.A. and Strayer D.L., 1996. Meiofauna. In: Houer F.R. and Lamberti G.A. (eds.), Methods in Stream Ecology, Academic Press, New York, 315-337.

Palmer M.A., Arensburger P., Silver Botts P., Hakenkamp C. and Reid J.W., 1995. Disturbance and the community structure of stream invertebrates: patch-specific effects and the role of refugia. Freshwater Biol., 34, 343-356.

Palmer M.A., Bely A.E. and Berg K.E., 1992. Response of invertebrates to lotic disturbance: a test of the hyporheic refuge hypothesis. Oecologia, 89, 182-194.

Panek K.L.J., 1991. Migrations of the macrozoobenthos within the bed sediments of a gravel stream (Ritrodat-Lunz study area, Austria). Verh. Internat. Verein. Limnol., 24, 1944 1947.

Pennak R.W., 1988. Ecology of freshwater meiofauna. In: Higgins R.P. and Thiel H. (eds.), Introduction to the Study of Meiofauna, Smithonian Institution Press, Washington, 39-60.

Piscart C., Moreteau J.-C. and Beisel J.-N., 2006. Monitoring changes in freshwater macroinvertebrate communities along a salinity gradient using artificial substrates. Environ. Monit. Assess., 116, 529-542.

Radwell A.J. and Brown A.V., 2008. Benthic meiofauna assemblage structure of headwater streams: density and distribution of taxa relative to substrate size. Aquat. Ecol., 42, 405-414.

Richards C. and Minshall G.W., 1988. The influence of periphyton abundance on Baetis bicaudatus distribution and colonization in a small stream. J. N. Am. Benthol. Soc., 7, 77-86.

Robertson A.L., 2000. Lotic meiofaunal community dynamics: colonisation, resilience and persistence in a spatially and temporally heterogeneous environment. Freshwater Biol., 44, 135-147.

Robertson A.L., Lancaster J. and Hildrew A.G., 1995. Stream hydraulics and the distribution of microcrustacea - a role for refugia. Freshwater Biol., 33, 469-484.

Robertson A.L., Rundle S.D. and Schmid-Araya J.M., 2000. Putting the meio- into stream ecology: current findings and future directions for lotic meiofaunal research. Freshwater Biol., 44, 177-183.
Rosenberg D.M. and Resh V.H., 1982. The use of artificial substrates in the study of freshwater benthic macroinvertebrates. In: Resh V.H. and Rosenberg D.M. (eds.), The Ecology of Aquatic Insects, Praeger, New York, 175-235.

Rouch R., 1991. Harpacticoid assemblages from a Pyrenean creek hyporheos. Ann. Limnol. - Int. J. Lim., 27, 227-241.

Schmid P.E., Tokeshi M., and Schmid-Araya J.M., 2000. Relation between population density and body size in stream communities. Science, 289, 1557-1560.

Schmid-Araya J.M., 2000. Invertebrate recolonization patterns in the hyporheic zone of a gravel stream. Limnol. Oceanogr., $45,1000-1005$.

Schmid-Araya J.M. and Schmid P.E., 1995. The invertebrate species of a gravel stream. Jber. Biol. Stn. Lunz, 15, 11-21.

Sharpe A.K. and Downes B.J., 2006. The effects of potential larval supply, settlement and post-settlement processes on the distribution of two species of filter-feeding caddisflies. Freshwater Biol., 51, 717-729.

Shaw D.W. and Minshall G.W., 1980. Colonization of an introduced substrate by stream invertebrates. Oikos, 34, 259-271.

Silver P., Palmer M.A., Swan C.M. and Wooster D., 2002. The small scale ecology of freshwater meiofauna. In: Rundle S.D., Robertson A.L. and Schmid-Araya J.M. (eds.), Freshwater Meiofauna: Biology and Ecology, Backhuys Publishers, Leiden, 217-239.

Sliva L. and Williams D.D., 2005. Responses of hyporheic meiofauna to habitat manipulation. Hydrobiologia, 548, $217-$ 232.

Smock L.A., 1994. Movements of invertebrates between stream channels and forested floodplains. J. N. Am. Benthol. Soc., 13, 524-531.

Söderström O., 1987. Upstream movements of invertebrates in running water - a review. Arch. Hydrobiol., 111, 197-208.

StatSoft Inc., 2008. STATISTICA (data analysis software system), version 8.1. www.stasoft.com.

Stead T.K., Schmid-Araya J.M. and Hildrew A.G., 2003. All creatures great and small: patterns in the stream benthos across a wide range of metazoan body size. Freshwater Biol., $48,532-547$.

Stead T.K., Schmid-Araya J.M. and Hildrew A.G., 2005. Secondary production of a stream metazoan community: does the meiofauna make a difference? Limnol. Oceanogr., 50, 398-403.

Stoch F., 1998. Moraria alpina n. sp. and redescription of Moraria radovnae Brancelj 1988, new rank, from Italian and Slovenian Alps (Crustacea, Copepoda, Harpacticoida). St. Trent. Sci. Nat., Acta Biol., 73, 135-145.

Stoch F., 2000-2006. CKmap for Windows. Version 5.3. Ministry for Environment, Territory and Sea, Nature Protection Directorate. Available online at: http://ckmap. faunaitalia.it

Stoch F. and Bruno M.C., 2011. Acanthocyclops magistridussarti sp. nov. from ground waters of peninsular Italy, with comments on the intraspecific variability of the antennary basis ornamentation (Copepoda, Cyclopoida, Cyclopidae). In: Defaye D., Suarez Morales E. and von Vaupel Klein J.C. (eds), Studies on Freshwater Copepoda, Brill, Leiden, 489-506.

Swan C.M. and Palmer M.A., 2000. What drives small scale spatial patterns in lotic meiofauna communities. Freshwater Biol., 44, 109-121. 
Townsend C.R., 1989. The patch dynamics concept of stream community ecology. J. N. Am. Benthol. Soc., 8, 36-50.

Townsend C.R. and Hildrew A.G., 1976. Field experiments on the drifting, colonization and continuous redistribution of stream benthos. J. Anim. Ecol., 45, 759-772.

Ward J.V., Bretschko G., Brunke M., Danielopol D., Gibert J., Gonser T. and Hildrew A.J., 1998. The boundaries of river systems: the metazoan perspective. Freshwater Biol., 40, 531-569.

Ward J.V., Malard F., Stanford J.S. and Gonser T., 2000. Interstitial aquatic fauna of shallow unconsolidated sediments, particularly hyporheic biotopes. In: Wilkens $\mathrm{H}$., Culver D.C. and Humphreys W.F. (eds.), Subterranean Ecosystems, Elsevier, Amsterdam, 41-58.

Ward J.V. and Palmer M.A., 1994. Distribution patterns of interstitial freshwater meiofauna over a range of spatial scales, with emphasis on alluvial river-aquifer systems. Hydrobiologia, 287, 147-156.
Williams D.D., 1984. The hyporheic zone as a habitat for aquatic insects and associated arthropods. In: Resh V.H. and Rosenberg D.M. (eds.), The Ecology of Aquatic Insects, Praeger, New York, 430-455.

Williams D.D. and Hynes H.B.N., 1974. The occurrence of benthos deep in the substratum of a stream. Freshwater Biol., 4, 233-256.

Williams D.D. and Hynes H.B.N., 1976. The recolonisation mechanisms of the stream benthos. Oikos, 27, 265-272.

Williams D.D. and Williams N.E., 1993. The upstream/downstream movement paradox of lotic invertebrates: quantitative evidence from a Welsh mountain stream. Freshwater Biol., 30, 199-218.

Winterbottom J.H., Orton S.E. and Hildrew A.G., 1997. Field experiments on the mobility of benthic invertebrates in a southern English stream. Freshwater Biol., 38, 37-47. 